
new online course in oral health education (OHE). A new way to learn a new skill and expand your horizons and career prospects, it is developed with established training providers OHE South West, and follows the success of the BDA's online course in dental radiography which has helped over 1,000 nurses gain the NEBDN radiography qualification.

The course consists of short, online modules which explain the scientific basis of oral health education and demonstrate the communication skills needed to educate patients. The modules can be taken on any broadband-connected computer and can be accessed at any time during the eight weeks of the course. BDA Education's tutors support students as they

\section{BETTER UNDERSTANDING ORAL HEALTH}

The Nottingham City Smiles programme recently circulated over 20,000 oral health packs to help create awareness of good oral health habits. The programme was set up to reduce the level of dental caries experience of all children in the city of Nottingham, to ensure children receive appropriate dental care, with particular emphasis on children in deprived electoral wards and to increase the knowledge about oral health by ensuring that accurate and consistent messages are promoted.

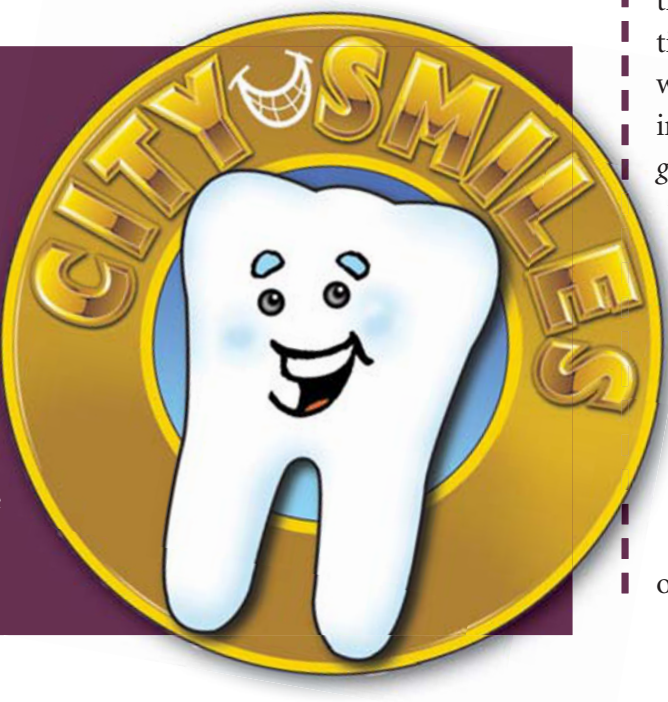
work and all study materials are provided in the price, including the textbook Basic guide to oral health education and promotion by Ann Felton.

The course is designed to prepare students for the NEBDN Certificate in Oral Health Education and provides up to 40 hours of CPD to participants. A course brochure and application form is available to download at www.bda. org/dcps. For more information, please contact BDA Education on 02075636891 or email ohe.support@bda.org.

\title{
HELPING THE POOR KEEP THEIR TEETH
}

Four volunteers recently completed a trip to India as part of a project known as 'Teeth for Life India' (TFL). Rachel Green, a Clinical Fellow in Oral Surgery at Newcastle University, Beth Young, a Staff Grade in Restorative Dentistry at Glasgow Dental Hospital, Laura Kerr, a GDP working in Dumfries and Helen Moore, a dental nurse based in the Oral Surgery department at Newcastle travelled to Bisalpur, a town in a rural area of Rajasthan, North West India, to carry out dental aid work.

TFL was formed in 2000 when the need for dental professionals was identified in Bisalpur. Many UK volunteers assisting at the adjoining eye hospital observed that dental care in this poor region was desperately needed. Since that time dental volunteers have helped for periods ranging from two weeks to two months.

The clinic comprises a dental unit together with a compressor, a new chair and an ultrasonic scaler and as most of the dental problems seen are preventable, TFL has also set up an education programme in the local schools and villages to provide dental health education and distribute oral health packs, containing toothbrushes and toothpaste.

If you would like to get involved with TFL, please contact dental nurse Helen Moore for further information by emailing helen.moore@ nuth.nhs.uk

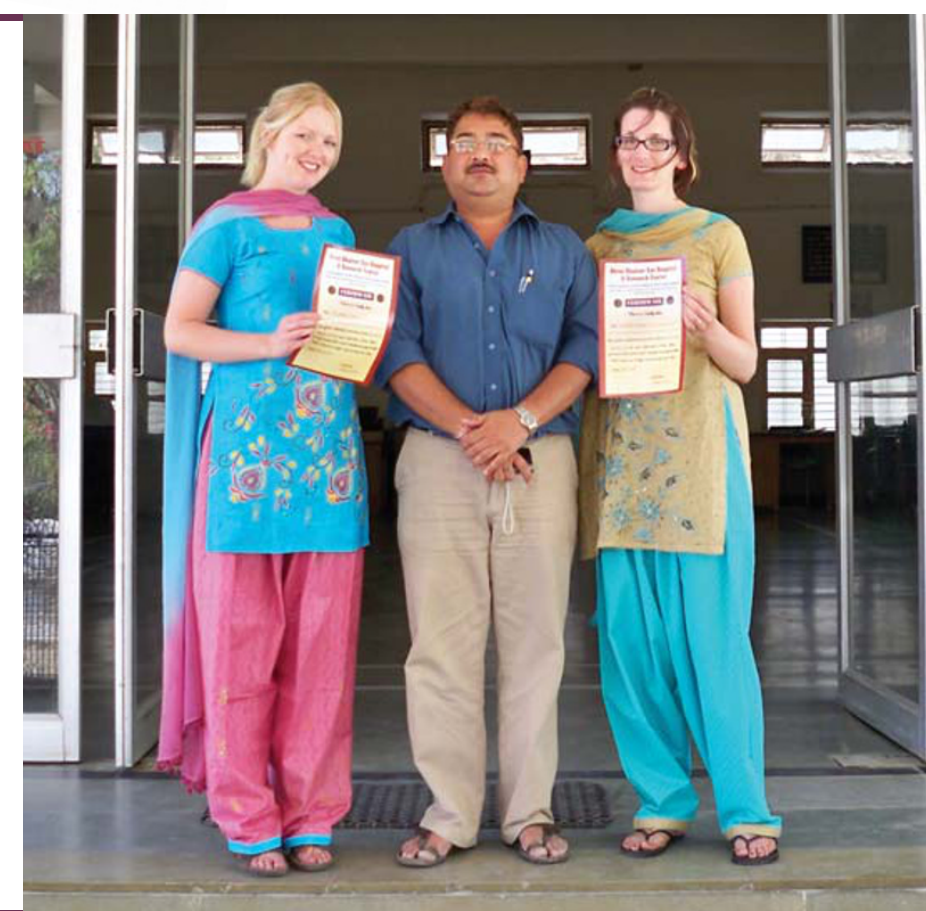

